\title{
Synthesis of Mesoporous Carbon from Merbau Wood (Intsia spp.) by Microwave Method as Ni Catalyst Support for a-Cellulose Hydrocracking
}

\author{
Andaru Dena Prasiwi, Wega Trisunaryanti ${ }^{*}$ Triyono, Iip Izul Falah, Darma Santi, and Muhammad \\ Fajar Marsuki \\ Department of Chemistry, Faculty of Mathematics and Natural Sciences, Universitas Gadjah Mada, \\ Sekip Utara, Yogyakarta 55281, Indonesia
}

\section{*Corresponding author:}

tel: $+62-811256055$

email:wegats@ugm.ac.id

Received: March 22, 2018

Accepted: February 11, 2019

DOI: $10.22146 / \mathrm{ijc} .34189$

\begin{abstract}
Synthesis of mesoporous carbon from merbau wood (Intsia spp.) waste by microwave method as nickel catalyst support for $\alpha$-cellulose hydrocracking had been carried out. The merbau wood sawdust was carbonized at $800{ }^{\circ} \mathrm{C}$ to produce C800, and the C800 was treated by microwave irradiation ( $399 \mathrm{~W})$ for 5 min to produce C800MW. The merbau wood flakes, which were only treated by microwave irradiation (399 Watts) for 30 min produced CMW. Wet impregnation technique was carried out to disperse the Ni metal (1.0, 1.5, and $2.0 \mathrm{wt} . \%)$ onto the best mesoporous carbon. The mesoporous carbons were analyzed by Fourier Transform Infra-Red Spectroscopy (FTIR), Surface Area Analyzer (SAA) and Scanning Electron Microscopy (SEM). The hydrocracking of pyrolyzed $\alpha$-cellulose was carried out at $400{ }^{\circ} \mathrm{C}$. The liquid product was analyzed by Gas Chromatography-Mass Spectrometer (GC-MS). The results showed that the C800MW was the best performance carbon and it had a specific surface area, total pore volume, average pore diameter and acidity of $364.12 \mathrm{~m}^{2} / \mathrm{g}, 0.28 \mathrm{~cm}^{3} / \mathrm{g}, 3.03 \mathrm{~nm}$, and $2.18 \mathrm{mmol} / \mathrm{g}$, respectively. The Ni1.5/C800MW catalyst produced the highest conversion of liquid product (58.76 wt.\%) than the Ni1/C800MW (57.51 wt.\%) and Ni2/C800MW (34.18wt.\%).
\end{abstract}

Keywords: Merbau wood; mesoporous carbon; microwave; nickel catalyst

\section{- INTRODUCTION}

Cellulose is one of the main compounds of biomass. Furthermore, it is abundant in nature [1-2]. Cellulose has several advantages such as renewable and biodegradable. The type of cellulose, which is the most stable form, is a-cellulose. The a-cellulose is mostly found in a wood with a content of more than 95 wt.\% [3]. High-value chemicals can be obtained from this $a$-cellulose by breaking its $\mathrm{C}-\mathrm{C}$ bond to form a shorter chain of hydrocarbon compounds via hydrocracking reaction [45]. To improve the yield of the hydrocracking product, a catalyst must be required in the reaction. The transition metal is usually used as catalysts in the hydrocracking process because they have acid sites which can initiate the hydrocracking reaction [6-8]. However, the transition metal cannot be directly used due to their capability to form agglomerates. This problem can be overcome by dispersing the transition metal on a porous material such as mesoporous carbon, MCM-41, and mesoporous silica. The mesoporous materials as a support catalyst will increase the catalyst's surface area and the reaction selectivity as well as prevent the agglomeration.

Synthesis of mesoporous carbon often needs a template to lead the formation of mesoporous in high temperature [9-11]. However, recent studies showed that the mesoporous carbon can be synthesized without a template and this is certainly more environmentally friendly. Carbonization process also needs an optimum temperature. If the carbonization temperature is too high, the reaction will produce more amount of gaseous product. On the other hand, a lower temperature cannot provide sufficient energy to synthesize mesoporous carbon [11]. As an alternative heating method, the researchers started to use microwave irradiation due to 
its possibility to produce activated carbon in a fast and easy way [12].

Merbau (Intsia spp.) which is known as a source of high-quality wood [13], has generated a lot of sawdust in its industrial processing. The sawdust consists of biomass chemical compounds such as lignin, cellulose, and hemicellulose [14]. This sawdust of merbau has great potential as a source of carbon. Therefore, the mesoporous carbons in this work were synthesized from merbau sawdust. The effect of microwave irradiation on the characters of mesoporous carbons was studied. The mesoporous carbon was used as a support material for $\mathrm{Ni}$ catalyst, and its catalytic activity was evaluated in hydrocracking of $\alpha$-cellulose.

\section{- EXPERIMENTAL SECTION}

\section{Materials}

Merbau sawdust was collected from local industries of wood processing in Manokwari Regency, West Papua, Indonesia. $\alpha$-Cellulose was obtained from Sigma-Aldrich. Pyridine, ethanol, and $\mathrm{NiCl}_{2} \cdot 6 \mathrm{H}_{2} \mathrm{O}$ were purchased from Merck.

\section{Instrumentation}

The surface parameters (surface area, pore volume, and pore diameter) of the mesoporous carbons were measured using Surface Area Analyzer (SAA, Quantachrome NovaWin Series). The measurement was based on physical adsorption of $\mathrm{N}_{2}$ gas at a batch temperature of $77.3 \mathrm{~K}$. The mesoporous carbons were degassed at $300{ }^{\circ} \mathrm{C}$ for $3 \mathrm{~h}$. The functional groups of mesoporous carbons were elucidated using Fourier Transform Infra-Red Spectroscopy (FTIR, Shimadzu Prestige-21) equipped with data station in the range of $4000-400 \mathrm{~cm}^{-1}$ with a $\mathrm{KBr}$ disc technique. The surface morphology of the mesoporous carbons was taken using a Scanning Electron Microscope (SEM, JEOL JSM06510LV). The imaging was carried out at $30 \mathrm{kV}$ accelerating voltage using the backscattered electron imaging technique. The liquid products obtained in the hydrocracking process of $\alpha$-cellulose were analyzed using Gas Chromatography-Mass spectrometer (GC-MS, Shimadzu QP2010S) with a column length of $30 \mathrm{~m}$, the diameter of $0.25 \mathrm{~mm}$, the thickness of $0.25 \mu \mathrm{m}$, the temperature of $60-310{ }^{\circ} \mathrm{C}$, helium gas as a carrier gas and an acceleration voltage of $70 \mathrm{Ev}$.

\section{Procedure}

\section{Synthesis of mesoporous carbons}

The merbau sawdust $(100 \mathrm{~g})$ was dried at $50{ }^{\circ} \mathrm{C}$. The dry merbau sawdust was heated at $800^{\circ} \mathrm{C}$ for $2 \mathrm{~h}$ under $\mathrm{N}_{2}$ gas stream with a flow rate of $20 \mathrm{~mL} / \mathrm{min}$ to produce $\mathrm{C} 800$. About $50 \mathrm{~g}$ of the $\mathrm{C} 800$ was treated with microwave irradiation for $5.3 \mathrm{~min}$ and $399 \mathrm{~W}$ to produce C800MW. Fifty grams of merbau sawdust was only treated with microwave irradiation for $30 \mathrm{~min}$ and 399 $\mathrm{W}$ to produce CMW. All samples were sieved with a 50 mesh strainer. The C800, C800MW, and CMW were analyzed using FTIR spectroscopy and SAA. The best performance carbon was analyzed using SEM.

\section{Preparation of catalysts}

$\mathrm{Ni}$ metal was impregnated onto the best performance carbon with a wet impregnation technique. Amounts of $\mathrm{Ni}$ metals were about 1.0, 1.5 and $2.0 \mathrm{wt} . \%$ toward the amount of carbon. The $\mathrm{NiCl}_{2} \cdot 6 \mathrm{H}_{2} \mathrm{O}$ salt was dissolved in deionized water. The carbon was then added to the salt solution. The mixture was stirred for $2 \mathrm{~h}$ at $80^{\circ} \mathrm{C}$. The solid was dried at $90^{\circ} \mathrm{C}$ for $7 \mathrm{~h}$. The solid was then calcined at $400{ }^{\circ} \mathrm{C}$ under nitrogen gas stream with a flow rate of $20 \mathrm{~mL} / \mathrm{min}$ for $3 \mathrm{~h}$ and followed by the reduction process at $400{ }^{\circ} \mathrm{C}$ under hydrogen gas stream with a flow rate of $20 \mathrm{~mL} / \mathrm{min}$ for $3 \mathrm{~h}$. The final products were $\mathrm{Nix} /$ carbon catalysts $(\mathrm{x}=1,1.5$ or 2$)$. Amounts of $\mathrm{Ni}$ metals loaded on to the best carbon catalysts were measured through the AAS method and their acidity value was determined by acidity test using the pyridine adsorption method.

\section{Acidity test}

The acidity value of the catalysts was measured by streaming the pyridine vapor onto the sample in a vacuum chamber for $24 \mathrm{~h}$ at room temperature. The acidity value of the catalysts was calculated using the following equation:

Acidity Value $=$

weight of sample after adsorption - weight of sample before adsorption weight of sample before adsorption $\times$ molecular weight of pyridine 


\section{Hydrocracking of a-cellulose}

The hydrocracking of $\alpha$-cellulose was performed in a two-step. The first step was pyrolysis of $\alpha$-cellulose at $600{ }^{\circ} \mathrm{C}$ for $3 \mathrm{~h}$ under nitrogen gas stream with a flow rate of $20 \mathrm{~mL} / \mathrm{min}$ in a stainless steel semi-batch reactor. The second step was hydrocracking of $\alpha$-cellulose pyrolysis oil which was obtained from the first step using the catalysts at $400{ }^{\circ} \mathrm{C}$ for $2 \mathrm{~h}$ under hydrogen gas stream with a flow rate of $30 \mathrm{~mL} / \mathrm{min}$ in a stainless steel semi-batch reactor (catalyst/feed ratio was about 1/30). The liquid products were analyzed using GC-MS.

\section{- RESULTS AND DISCUSSION}

\section{Characterization of Mesoporous Carbon}

Table 1 presented the surface parameters of the mesoporous carbons synthesized in this work. The SAA analysis results showed that the C800MW had the highest specific surface area than the others. In another side, the C800 also had a higher specific surface area than the CMW. However, the heating method in the synthesis of mesoporous carbon could not stand alone. The microwave irradiation was still required to enlarge the pores. This phenomenon may be caused by the selectivity of microwave irradiation in heating polar molecules. Non-polar molecules are inert toward the microwave radiation whereas polar molecules can absorb electromagnetic energy of microwave. Polar molecules tend to align in the electromagnetic field, and it produces heat due to the friction caused by slower reorientation of the molecules [15-17]. The collision probability of molecules will increase as the molecular motion accelerates and causing the reaction rate to increase. The microwave heating method is possible to produce activated carbon quickly and easily. Microwaves irradiation has become an alternative in the preparation of activated carbon.

Isothermal adsorption of mesoporous carbon

Table 1. Surface parameters of mesoporous carbons

\begin{tabular}{lccc}
\hline Sample & $\begin{array}{l}\text { Surface area } \\
\left(\mathrm{m}^{2} / \mathrm{g}\right)\end{array}$ & $\begin{array}{l}\text { Total pore } \\
\text { volume }\left(\mathrm{cm}^{3} / \mathrm{g}\right)\end{array}$ & $\begin{array}{l}\text { Average pore } \\
\text { diameter }(\mathrm{nm})\end{array}$ \\
\hline C800 & 136.00 & 0.18 & 5.29 \\
C800MW & 364.12 & 0.28 & 3.03 \\
CMW & 38.09 & 0.08 & 8.48 \\
\hline
\end{tabular}
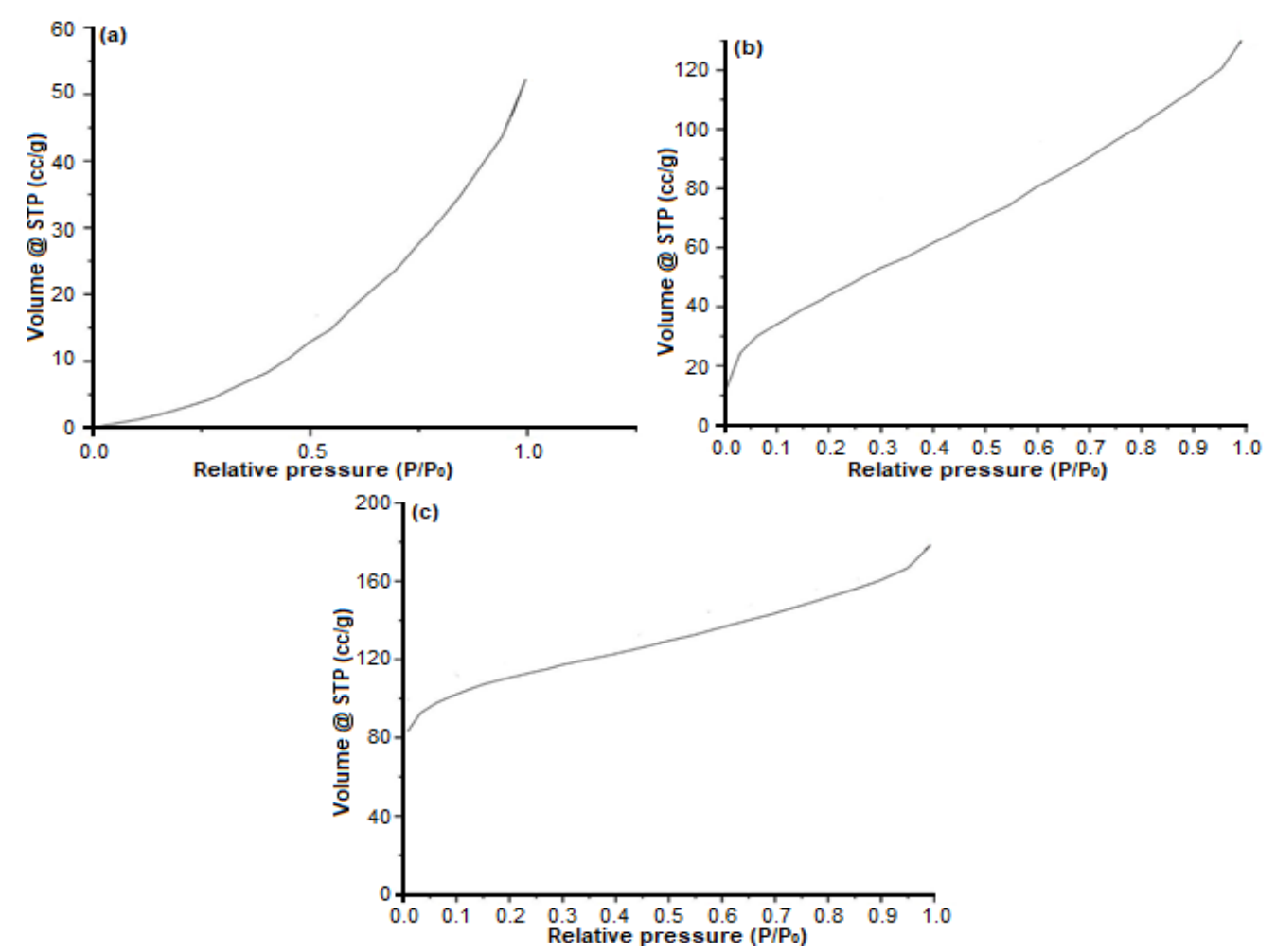

Fig 1. Isothermal adsorption of: (a) CMW, (b) C800, and (c) C800MW 
material was presented in Fig. 1. The carbon material of the CMW sample shows the pattern of carbon quantity as an adsorbent is higher when the pressure is relatively increased. This is because the interaction between $\mathrm{N}_{2}$ or adsorbate-adsorbate is stronger than that of the adsorbent-adsorbate so that the adsorbate clumps on a certain side of the surface. In the CMW carbon sample, the interaction that occurs is the attraction between the adsorbates which is relatively low and reversible. In the carbon samples, C800 and C800MW show convex lines on the $\mathrm{P} / \mathrm{P}_{0}$ axis which do not indicate the occurrence of monolayer-multilayer adsorption stages [18-19]. This result established that the C800MW was a better support catalyst than the C800 and CMW. Fig. 2 presented the SEM micrographs of the C800MW. The mesoporous surface of the C800MW grains had a pore that indicated a mesoporous structure was formed on the C800MW.

\section{Characterization of Ni/C800MW Catalysts}

The FTIR spectra of the C800MW and all Nix/C800MW catalysts before the acidity test were presented in Fig. 3. The C800MW and Nix/C800MW catalysts had hydroxyl groups $(\mathrm{OH})$ on their surface which was proved by the occurrence of an absorption peak at $3425 \mathrm{~cm}^{-1}$ in the FTIR spectra. Furthermore, the FTIR spectra also exhibited absorption peaks at 28462854 and $2916-2924 \mathrm{~cm}^{-1}$ which corresponded to the vibration of the $\mathrm{CH}$ groups in aliphatic compounds. The FTIR spectra of the C800MW and all Nix/C800MW catalysts after the acidity test were shown in Fig. 4. During

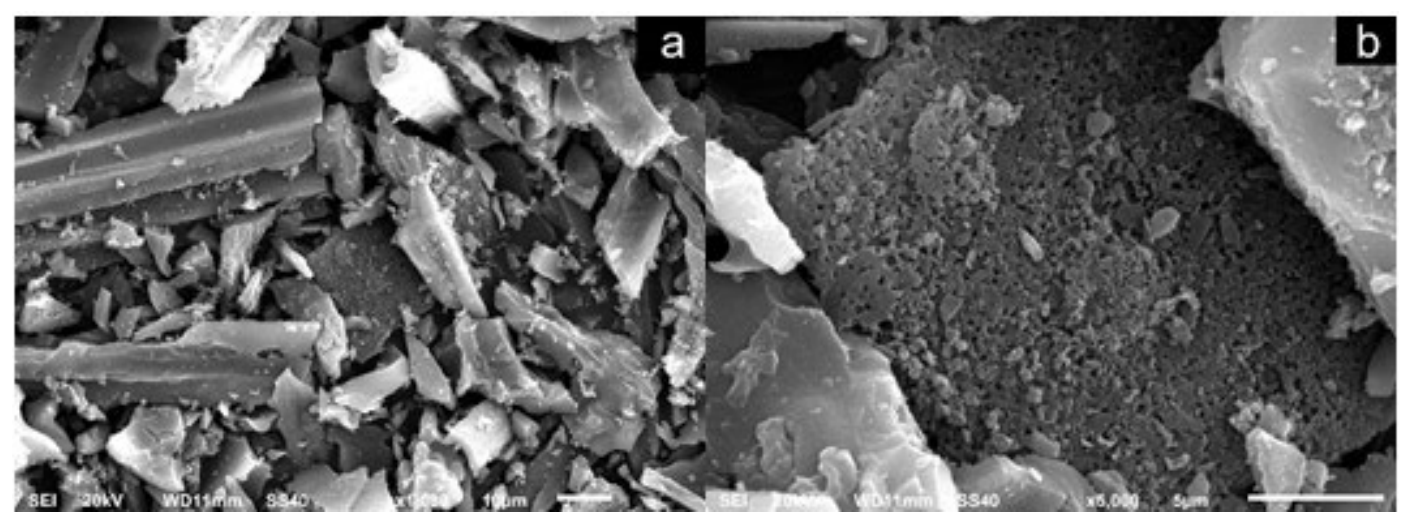

Fig 2. SEM micrograph of C800MW in magnification: (a) x1000 and (b) x5000

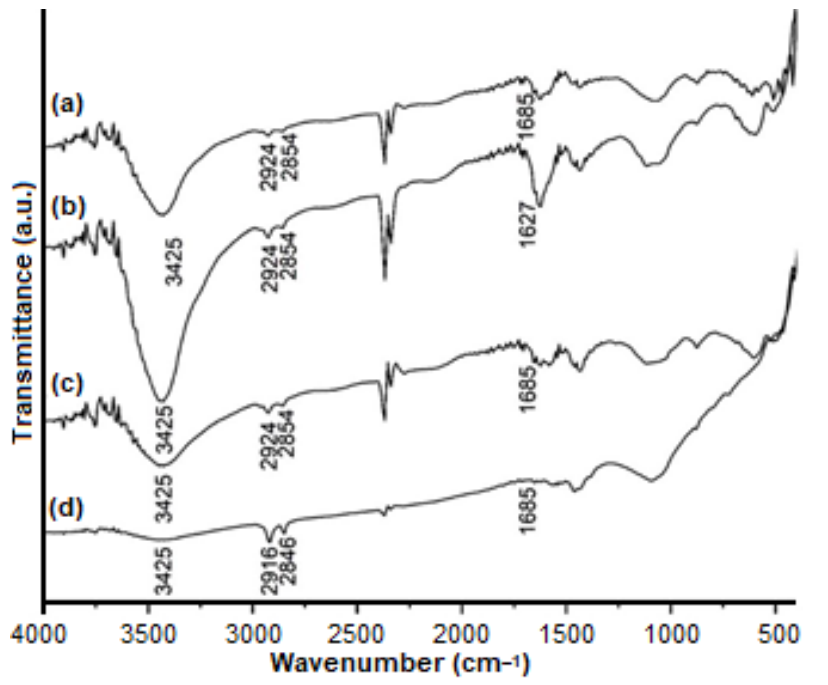

Fig 3. FTIR spectra of (a) Ni2/C800MW, (b) Ni1.5/C800MW, (c) Ni1/C800MW and (d) C800MW before pyridine adsorption

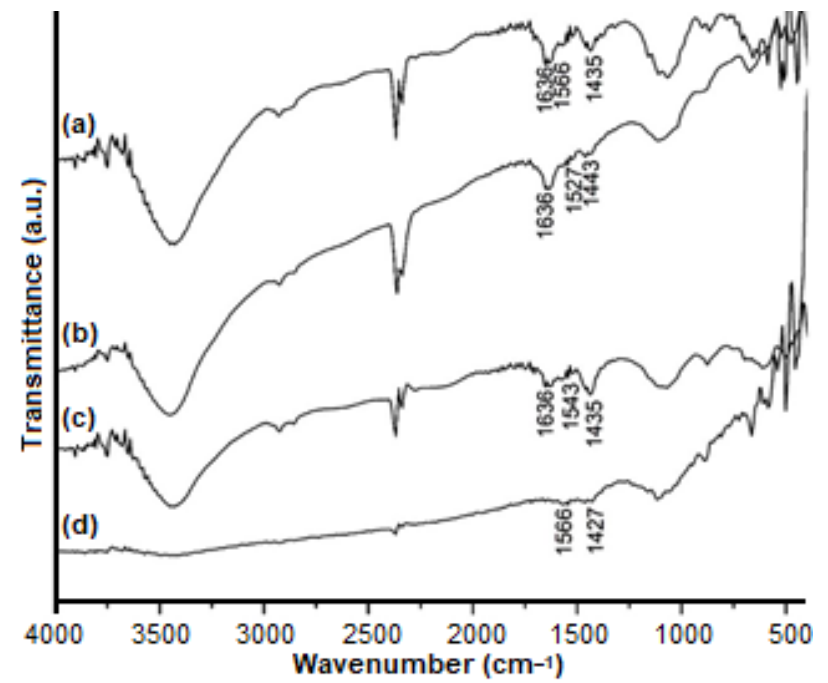

Fig 4. FTIR spectra of (a) Ni2/C800MW, (b) Ni1.5/C800MW, (c) Ni1/C800MW and (d) C800MW after pyridine adsorption acidity test, the C800MW and 
all Ni/C800MW catalysts adsorbed pyridine vapor and this lead to the occurrence of several additional absorption peaks in their FTIR spectra. The additional absorption peaks appearing at $1527-1566$ and $1636 \mathrm{~cm}^{-1}$ were recognized as Brønsted acid sites and the others appearing at $1427-1443 \mathrm{~cm}^{-1}$ were recognized as Lewis acid sites [20-21].

The amounts of Ni metals loaded onto the C800MW were measured through the AAS method, and the results are presented in Table 2. The amount of all impregnated $\mathrm{Ni}$ metals on the C800MW were lower than that of the initial amount of Ni metals loaded. These results may be caused by the amount of water in the nickel salt solution was changed during the storage. The amounts of Ni metal impregnated onto the C800MW linearly increased in accordance with the increasing of initially $\mathrm{Ni}$ amounts in a salt solution used in the impregnation process, but it decreased in Ni2/C800MW. The decreasing of amounts of Ni metals on the Ni2/C800MW catalyst was caused by the competition of relatively higher amount of Ni metals to disperse on the C800MW surface. The Ni ions collided each other, and this would increase their energy. The increasing of $\mathrm{Ni}$ ions energy prevented the ions to be bound with the C800MW surface.

Table 3 presented the acidity values of the C800MW and those of the Nix/C800MW catalysts. Fig. 5 showed that the acidity values of the Nix/C800MW catalysts were proportional to the amounts of $\mathrm{Ni}$ metals loaded onto the C800MW. The highest acidity value was obtained in the Ni1.5/C800MW catalyst, and this was due to its highest amounts of Ni metals than the others. The Ni metal has empty $p$-orbitals which can accept lone pair electrons from nitrogen atom in pyridine molecule [22]. Nickel metal provides Lewis acid sites, and the increase of $\mathrm{Ni}$ amount leads to the increase of acidity.

\section{Catalysts Activity}

The Nix/C800MW catalysts were applied in hydrocracking of $a$-cellulose pyrolysis oil. In order to evaluate the catalysts activity, hydrocracking of a-cellulose pyrolysis oil without catalyst or usually called as thermal hydrocracking was also carried out in this work. The hydrocracking products distribution were presented in Fig. 6. The results showed that the thermal hydrocracking produced more gas than those of the

Table 2. AAS analysis result of catalysts

\begin{tabular}{lc}
\hline Catalyst & Ni Metal Content (wt.\%) \\
\hline C800MW & 0.00 \\
Ni1/C800MW & 0.31 \\
Ni1.5/C800MW & 0.55 \\
Ni2/C800MW & 0.27 \\
\hline
\end{tabular}

Table 3. Acidity value of catalysts

\begin{tabular}{lc}
\hline Sample & Acidity Value $(\mathrm{mmol} / \mathrm{g})$ \\
\hline C800MW & 2.18 \\
Ni1/C800MW & 3.03 \\
Ni1.5/C800MW & 3.30 \\
Ni2/C800MW & 2.91 \\
\hline
\end{tabular}

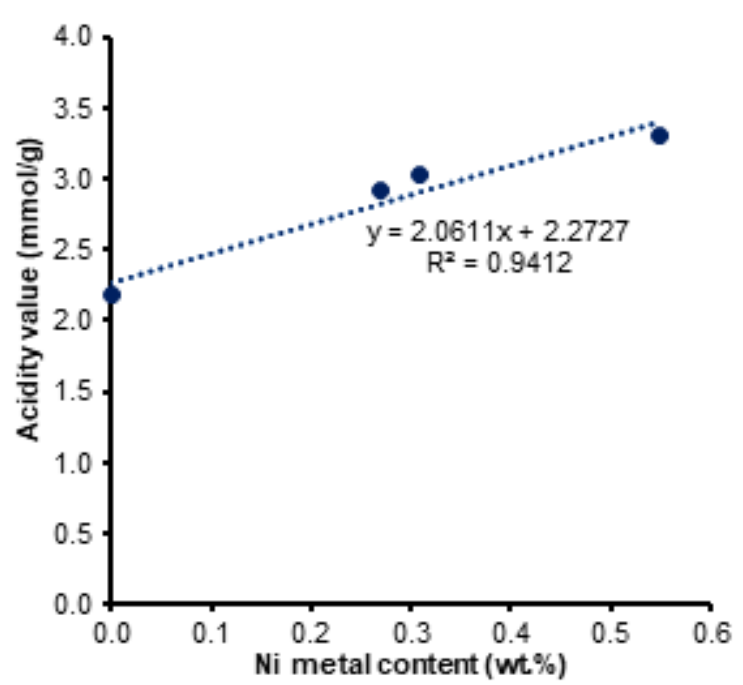

Fig 5. Relationship between the amounts of Ni towards acidity value

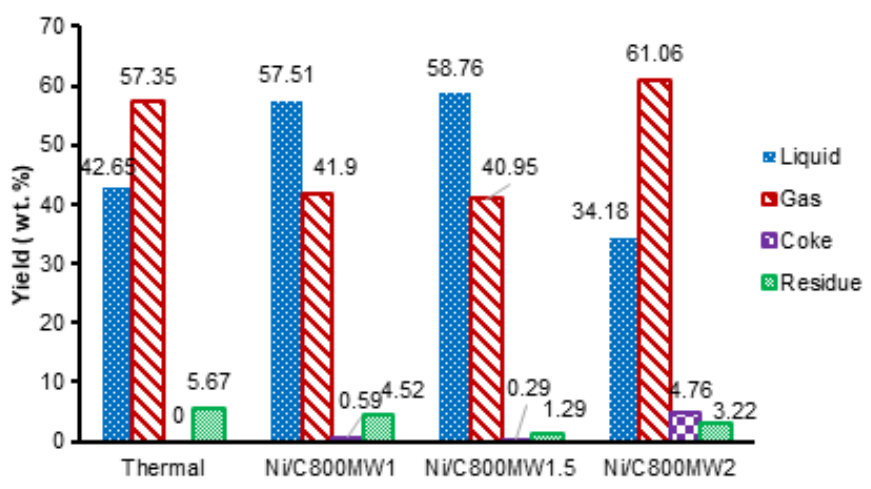

Fig 6. Products distribution of a-cellulose hydrocracking 
Table 4. Chemical composition of liquid products

\begin{tabular}{llllll}
\hline \multirow{2}{*}{ Compounds } & \multicolumn{5}{c}{ Yield (wt.\%) } \\
\cline { 2 - 6 } & Pyrolysis oil & Thermal & Ni1/C800MW & Ni1.5/C800MW & Ni2/C800MW \\
\hline $\begin{array}{l}\text { Ketones } \\
\text { 1-Hydroxy-2-propanone }\left(\mathrm{C}_{3} \mathrm{H}_{6} \mathrm{O}_{2}\right)\end{array}$ & 5.49 & 22.35 & 13.19 & 19.47 & 11.38 \\
$\begin{array}{l}\text { 1-Hydroxy-2-butanone }\left(\mathrm{C}_{4} \mathrm{H}_{8} \mathrm{O}_{2}\right) \\
\text { Aldehyde }\end{array}$ & 0.91 & 2.85 & 5.08 & 5.76 & 5.08 \\
$\begin{array}{l}\text { 2-Furan Carboxoxehyde }\left(\mathrm{C}_{5} \mathrm{H}_{4} \mathrm{O}_{2}\right) \\
\text { Carboxylic acid }\end{array}$ & 12.23 & 7.62 & 7.10 & 7.25 & 8.84 \\
Acetate acid $\left(\mathrm{C}_{2} \mathrm{H}_{4} \mathrm{O}_{2}\right)$ & & & & & \\
Propanoate acid $\left(\mathrm{C}_{3} \mathrm{H}_{6} \mathrm{O}_{2}\right)$ & 6.63 & 19.67 & 17.44 & 20.76 & 17.45 \\
Formic acid $\left(\mathrm{CH}_{2} \mathrm{O}_{2}\right)$ & 2.89 & 2.41 & 3.59 & 9.01 & 12.75 \\
\hline
\end{tabular}

hydrocracking using Nix/C800MW catalysts. This phenomenon was occurred due to the role of $\mathrm{Ni}$ metal, which has unpaired electrons in its $d$-orbitals. These unpaired electrons dissociated the hydrogen gas to initiate the hydrocracking reaction [18,23-24]. In another side, thermal hydrocracking reaction occurs through the formation of radical ions. These radical ions can break $\mathrm{C}-\mathrm{C}$ bond at the $\beta$ position in hydrocarbon compounds to form shorter-chain radical compounds. When these radicals combine each other, new hydrocarbon compounds will be formed, and they tend in the form of gas $[22,25]$. In contrast to the amount of gas produced, the hydrocracking of a-cellulose pyrolysis oil using the Nix/C800MW produced more amount of liquid product. The highest amount of liquid product was obtained in the hydrocracking of a-cellulose pyrolysis oil using the Ni1.5/C800MW catalyst. This result indicated that the Ni1.5/C800MW catalyst had the highest catalytic activity in the hydrocracking of $\alpha$-cellulose pyrolysis oil. The catalytic activity was proportional to its acidity value.

\section{Catalysts Selectivity}

Table 4 and Fig. 7 showed the chemical composition of liquid products obtained in this work. The thermal hydrocracking and hydrocracking using the Ni1/C800MW catalyst produced liquid products, which are mainly composed of 1-hydroxy-2-propanone (22.35\%) and formic acid (5.44\%) compared with the other samples. The hydrocracking using the

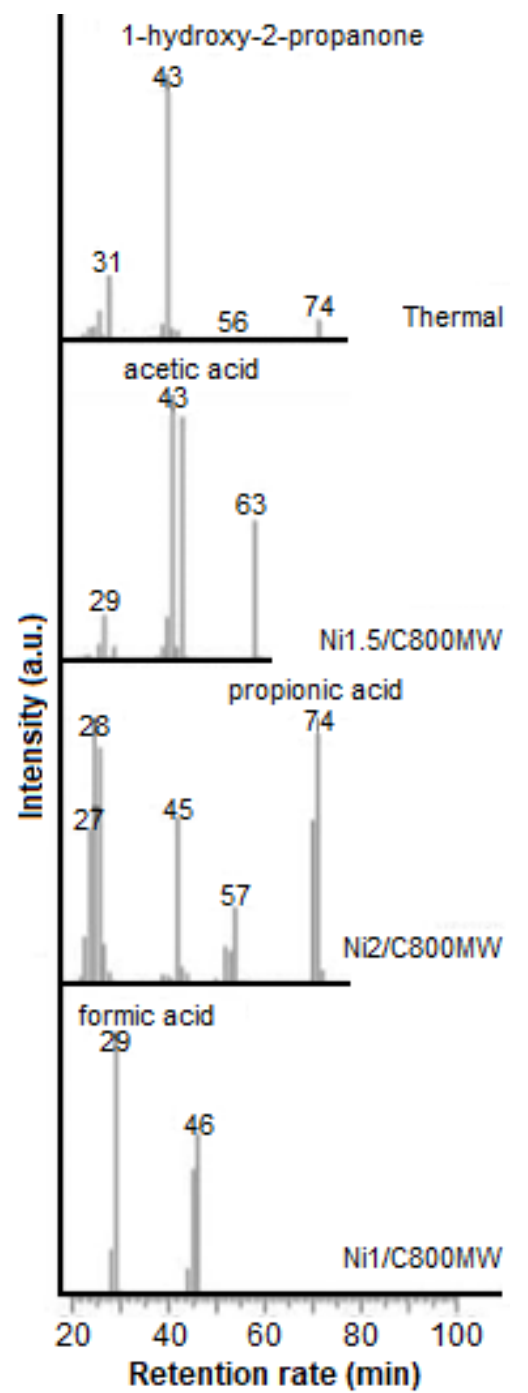

Fig 7. GC Chromatogram a) Thermal; b) Ni1.5/C800MW; c) Ni2/C800MW; d) Ni1/C800MW 
the other samples. The hydrocracking using the Ni2/C800MW catalyst exhibited liquid product, which was mainly composed of propionic acid (12.75\%) compared with the other samples. These results reveal that every catalyst synthesized in this work had its own selectivity in the production of certain chemicals. Therefore, microwave-pretreatment can improve recovery, yield, and quality of resulting oil.

\section{- CONCLUSION}

Synthesis of mesoporous carbon from merbau sawdust using heating followed by microwave simultaneously irradiation was the best method to produce the best performance mesoporous carbon (C800MW). The C800MW had a specific surface area, total pore volume, average pore diameter and acidity of $364.12 \mathrm{~m}^{2} / \mathrm{g}, 0.28 \mathrm{~cm}^{3} / \mathrm{g}$ and of $3.03 \mathrm{~nm}, 2.18 \mathrm{mmol} / \mathrm{g}$, respectively. The impregnation of $\mathrm{Ni}$ metals onto the C800MW would increase its acidity and catalytic activity. The highest amount of liquid product (58.76 wt.\%) was produced by Ni1.5/C $800 \mathrm{MW}$ catalyst in the hydrocracking of $\alpha$-cellulose.

\section{- ACKNOWLEDGMENTS}

This research work was financially supported by The Indonesian Ministry of Research Technology and Higher Education under the scheme of PDUPT 2018 research Grant (Contract number: 85/UN1/DITLIT/DITLITLIT/LT/2018).

\section{- REFERENCES}

[1] Krutof, A., and Hawboldt, K., 2016, Blends of pyrolysis oil, petroleum, and other bio-based fuels: A review, Renewable Sustainable Energy Rev., 59, 406419.

[2] Zhao, C., Jiang, E., and Chen, A., 2017, Volatile production from pyrolysis of cellulose, hemicellulose and lignin, J. Energy Inst., 90 (6), 902-913.

[3] Vismara, E., Gastaldi, G., Valerio, A., Bertini, S., Cosentino, C., and Eisle, G., 2009, Alpha cellulose from industrial and agricultural renewable sources like short flax fibres, ears of corn and wheat-straw and its transformation into cellulose acetates, $J$. Mater. Chem., 19 (45), 8678-8686.
[4] Collard, F.X., and Blin, J., 2014, A review on pyrolysis of biomass constituents: mechanisms and composition of the products obtained from the conversion of cellulose, hemicelluloses and lignin, Renewable Sustainable Energy Rev., 38, 594-608.

[5] Stefanidis, S.D., Kalogiannis, K.G., Iliopoulou, E.F., Michailof, C.M., Pilavachi, P.A., and Lappas, A.A., 2014, A study of lignocellulosic biomass pyrolysis via the pyrolysis of cellulose, hemicellulose and lignin, J. Anal. Appl. Pyrolysis, 105, 143-150.

[6] Upare, D.P., Park, S., Kim, M.S., Jeon, Y.P., Kim, J., Lee, D., Lee, J., Chang, H., Choi, S., Choi, W., Park, Y.K., and Lee, C.W., 2017, Selective hydrocracking of pyrolysis fuel oil into benzene, toluene and xylene over CoMo/beta zeolite catalyst, J. Ind. Eng. Chem., 46, 356-363.

[7] Majka, M., Tomaszewicz, G., and Mianowski, A., 2017, Experimental study on the coal tar hydrocracking process over different catalysts, $J$. Energy Inst., 91 (6), 1164-1176.

[8] Upare, D.P., Park, S., Kim, M.S., Kim, J., Lee, D., Lee, J., Chang, H., Choi, W., Choi, S., Jeon, Y.P., Park, Y.K., and Lee, C.W., 2016, Cobalt promoted mo/beta zeolite for selective hydrocracking of tetralin and pyrolysis fuel oil into monocyclic aromatic hydrocarbons, J. Ind. Eng. Chem., 35, 99107.

[9] Ulfa, M., Trisunaryanti, W., Falah, I.I., and Kartini, I., 2016, wormhole-like mesoporous carbons from gelatine as multistep infiltration effect, Indones. J. Chem., 16 (3), 239-242.

[10] Ulfa, M., Trisunaryanti, W., Falah, I.I., and Kartini, I., 2015, Characterization of gelatines extracted from cow bone for carbon synthesis, IOSR J. Appl. Chem., 8 (8), 57-63.

[11] Pongsendana, M., Trisunaryanti, W., Artanti, F.W., Falah, I.I., and Sutarno, 2017, Hydrocracking of waste lubricant into gasoline fraction over CoMo catalyst supported on mesoporous carbon from bovine bone gelatin, Korean J. Chem. Eng., 34 (10), 2591-2596.

[12] Thue, P.S., Lima, E.C., Sieliechi, J.M., Saucier, C., Dias, S.L.P., Vaghetti, J.C.P., Rodembusch, F.S., and 
Pavan, F.A., 2017, Effects of first-row transition metal and impregnation ratios on the physicochemical properties of microwave-assisted activated carbons from wood biomass, J. Colloid Interface Sci., 486, 163-175.

[13] Xu, Q., Chen, L., Harries, K.A., Zhang, F., Liu, Q., and Feng, J., 2015, Combustion and charring properties of five common constructional wood species from cone calorimeter tests, Constr. Build. Mater., 96, 416-427.

[14] Bridgwater, A.V., and Peacocke, G.V.C., 2000, Fast pyrolysis processes for biomass, Renewable Sustainable Energy Rev., 4 (1), 1-73.

[15] Senise, J.T., and Jermolovicius, L.A., 2004, Microwave chemistry - A fertile field for scientific research and industrial applications, J. Microwaves Optoelectron., 5 (4), 97-112.

[16] Lidström, P., Tierney, J., Wathey, B., and Westman, J., 2001, Microwave-assisted organic synthesis-A review, Tetrahedron, 57 (45), 9225-9283.

[17] Buchachenko, A.L., 2000, Recent advances in spin chemistry, Pure Appl. Chem., 72 (12), 2243-2258.

[18] Masykuroh, A., Trisunaryanti, W., Falah, I.I., and Sutarno, 2016, Preparation and characterization of Co and Co-Mo loaded on mesoporous silica for hydrocracking of waste lubricant, Int. J. ChemTech Res., 9 (9), 598-606.

[19] Trisunaryanti, W., Lisna, P.S., Kartini, I., Sutarno, Falah, I.I., and Triyono, 2016, Extraction of gelatin from bovine bone and its use as template in synthesis of mesoporous silica, Asian J. Chem., 28 (5), 996-1000.
[20] Song, K., Guan, J., Wu, S., and Kan, Q., 2009, Synthesis and characterization of strong acidic mesoporous alumino-silicates constructed of zeolite MCM-22 precursors, Catal. Commun., 10 (5), 631-634.

[21] Kumaran, G.M., Garg, S., Soni, K., Kumar, M., Gupta, J.K., Sharma, L.D., Rao, K.S.R., and Dhar, G.M., 2008, Synthesis and Characterization of Acidic Properties of Al-SBA-15 Materials with Varying Si/Al Ratios, Microporous Mesoporous Mater., 114 (1-3), 103-109.

[22] Kusumastuti, H., Trisunaryanti, W., Falah, I.I., and Marsuki, M.F., 2018, Synthesis of mesoporous silica-alumina from lapindo mud as a support of $\mathrm{Ni}$ and Mo metals catalysts for hydrocracking of pyrolyzed a-cellulose, Rasayan J. Chem., 11 (2), 522-530.

[23] Salim, I., Trisunaryanti, W., Triyono, and Arryanto, Y., 2016, Hydrocracking of coconut oil into gasoline fraction using $\mathrm{Ni} /$ modified natural zeolite catalyst, Int. J. ChemTech Res., 9 (4), 492-500.

[24] Nurmalasari, Trisunaryanti, W., Sutarno, and Falah, I.I., 2016, Mesoporous silica impregnated by $\mathrm{Ni}$ and NiMo as catalysts for hydrocracking of waste lubricant, Int. J. ChemTech Res., 9 (9), 607614.

[25] Sriningsih, W., Saerodji, M.G., Trisunaryanti, W., Triyono, Armunanto, R., and Falah, I.I., 2014, Fuel production from LDPE plastic waste over natural zeolite supported $\mathrm{Ni}, \mathrm{Ni}-\mathrm{Mo}, \mathrm{Co}$ and $\mathrm{Co}-\mathrm{Mo}$ metals, Procedia Environ. Sci., 20, 215-224. 